\title{
EL ORIGEN GEOLÓGICO, GALAICO, DEL EJEMPLAR DE MARABIU (TEVERGA, ASTURIAS) Y CONSIDERACIONES CULTURALES SOBRE LOS ÚTILES-ARMA, CALIFICADOS DE "HACHAS NÓRDICAS", DEL NOROESTE IBÉRICO
}

\author{
THE GEOLOGICAL ORIGIN, GALICIEN, OF THE MARABIU EXAMPLE (TEVERGA, \\ ASTURIAS) AND CULTURAL CONSIDERATIONS ON WEAPON-TOOLS CLASSIFIED AS \\ “NORTHERN BATTLE-AXES” IN THE NW OF IBERIA
}

\author{
MIGUEL A. DE BLAS CORTINA (*) \\ L. GUILLERMO CORRETGÉ CASTAÑ́N (**)
}

\section{RESUMEN}

El análisis físico de un ejemplar perforado del centro de Asturias (Marabiu) prueba que su solitaria presencia en la Región Cantábrica se debe a una importación desde Galicia (cianitas de Touro, al E de Santiago de Compostela). La concentración de estos útiles-arma en túmulos del III milenio en Galicia (Coruña y O de Lugo) dibuja el foco único en la Península Ibérica de un fenómeno bien conocido en Europa. En el artículo se ofrecen argumentos geográficos, económicos y culturales justificativos de la presencia singular de estos "cetros" o símbolos de estatus, de su carácter local aunque se aprecien resonancias de tipos de NO continental, lo que hizo que se calificara a los perforados gallegos de "hachas de combate nórdicas".

\begin{abstract}
The physical analysis of a perforated item from Asturias shows that its only presence in the Cantabric region is due to an import from Galicia (cianites of Touro, near Santiago de Compostela). The concentration of these tool-weapons in barrows of the III millenium in Galicia is a unique focus in the Iberian peninsula of a very well known phenomenon in Europe. In this article, geographic, economic and cultural arguments are offered, justifiyng the peculiar presence of these sceptres or status symbols and of their local

(*) Dpto. de Historia (Prehistoria). Universidad de Oviedo. C/ Tte. Alfonso Martínez, s/n. 33011 Oviedo.

(**) Dpto. de Geología. Universidad de Oviedo. C/ Jesús Arias de Velasco, s/n. 33005 Oviedo. Correo electrónico: corretge@ asturias.gcol.uniovi.es

El artículo fue remitido en su versión final el 25-V-2001.
\end{abstract}

character, although they remind us of types in the continental NW, so that the Galician perforated tools are classified as "northern battle-axes".

Palabras clave: Hachas de combate. Origen geológico. Calcolítico. Estatus social. Cambio cultural. NO ibérico.

Key words: Battle axes. Geological origin. Chalcolithic. Social status. Cultural change. Iberian NW.

Durante un par de horas de un domingo de nieves de 1973 pudimos disponer del perforado del Fondadal, en Marabiu, Teverga. Fue el tiempo justo para un somero análisis visual, realizar su primer dibujo y algunas fotografías. Las facilidades que entonces nos concediera su propietario fueron escasas e inútil nuestro intento de que la pieza pasara al Museo Arqueológico deAsturias. De los datos recogidos partió la redacción de un breve artículo en el que se expresaba la singularidad del objeto, tentándose la aproximación a su contexto cultural y a su cronología (Blas Cortina, 1973). Poco después se tornó incierto su paradero hasta que el arqueólogo Rogelio Estrada pudo localizarla de nuevo, incluyéndola en la exposición por él organizada, bajo el título Patrimonio arqueológico en el concejo de Grado, en la Casa de la Cultura de la villa asturiana de Grado en el mes de abril de 2000.

La reaparición de la pieza, tras más de un cuarto de siglo, nos permitió lo que fuera imposible en la primera oportunidad: un análisis reposado más allá de la mera apreciación visual, buscando establecer, mediante los procedimientos analíticos per- 

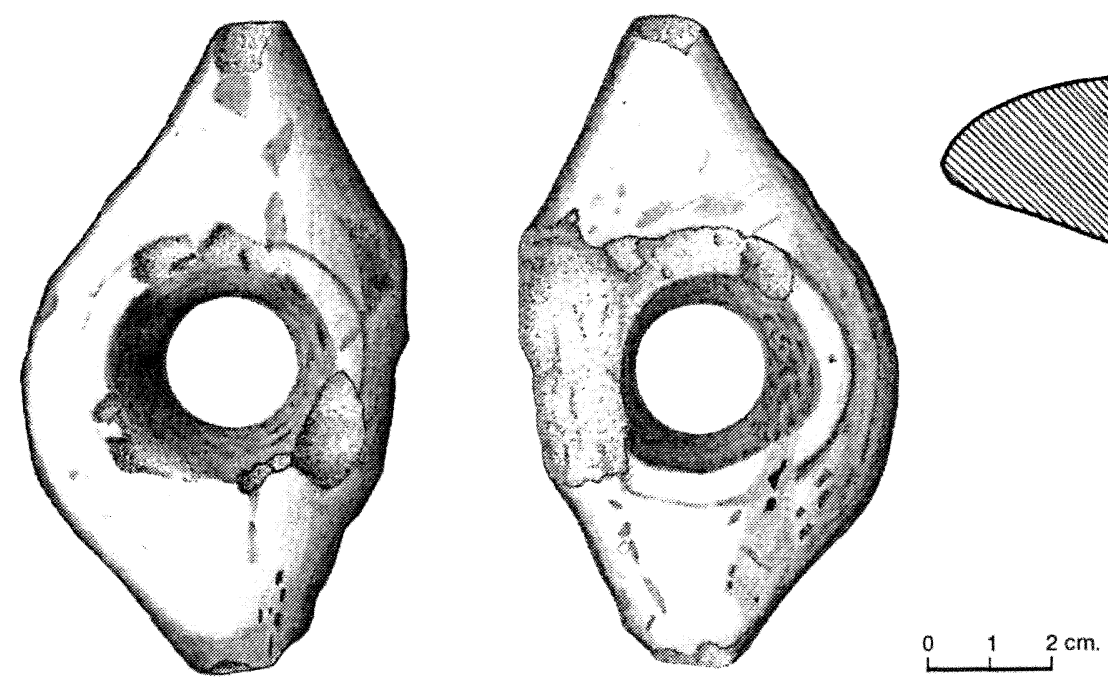

Fig. 1. Doble pico perforado de Marabiu y propuesta de enmangue (dibujo de G. Álvarez Toledo, M.A. de Blas y J. L. Seoane).

tinentes, tanto su naturaleza petrográfica como la probable localización geográfica de la roca original.

El descubrimiento del útil-arma, en un momento impreciso de los años treinta, se produjo en los puertos de Marabiu, en el lugar de Fondadal, en cotas de altitud cercanas a los $1000 \mathrm{~m}$. El enclave, sito en el costado oeste de una vaguada a la que flanquean crestones calcáreos, se encuentra próximo al camino real que une el territorio de Teverga, en la cuenca hidrográfica del Nalón, con el de Yernes y Tameza al norte. El área de Marabiu muestra como vestigios arqueológicos los restos de algunos túmulos de pequeñas dimensiones; otros, con mayor entidad, se observan a lo largo de la señalada vía.

El hallazgo que nos ocupa fue accidental, al cavar una presa de regadío; no hay posibilidad, partiendo de vagos informes orales, de precisar si guarda alguna relación con una supuesta sepultura, limitada únicamente a "piedras y cenizas", descubierta por entonces en el mismo área.

\section{CARACTERIZACIÓN MINERALÓGICA Y GEOLÓGICA}

La pieza (Fig. 1) es mineralógicamente singular. La imposibilidad de disponer de muestra suficiente para su identificación mediante análisis destructivos determinó que todas las técnicas de caracterización hayan sido físicas, respetándo al máximo la integridad del objeto.
- Análisis de visu: es un objeto de 290 gramos, de superficie muy pulimentada, tacto cuarcítico y densidad notable. Presenta una fractura que permitió afinar la determinación e, incluso, extraer con torno de dentista 1-2 milímetros cúbicos de polvo para análisis difractométrico.

Se observa que la estructura composicional es ligeramente heterogénea según el eje longitudinal de la pieza. La heterogeneidad viene determinada por la presencia de una banda irregular, de $3 \mathrm{~cm}$ de lóngitud por $1 \mathrm{~cm}$ de anchura máxima, de material policristalino de color pardo amarillento moderado (10YR 5/4 en la escala Munsell). La observación con lupa binocular permite apreciar, en dicha zona, cristalitos de cuarzo, pajuelas de moscovita y algunas masas milimétricas, singulares, de turmalina. Los mismos minerales suelen aparecer ocasionalmente en el resto del hacha que ofrece un cierto aspecto heterogéneo, dado que en el fondo de color gris verdoso predominante (5 GY 6/1) aparecen algunos hilillos anostomosados de grosor inferior al milímetro y de color gris más oscuro.

- Dureza: fueron realizadas varias microincisiones para averiguar la dureza según la escala convencional de Mohs. Los valores obtenidos son próximos a 6 , que es el valor que tienen los feldespatos, y es ligeramente inferior a la dureza del cuarzo.

- Densidad: se siguió el método de la balanza hidrostática, consistente en establecer las relaciones de peso en seco y en immersión. Los valores obtenidos proporcionaron una densidad de 3247 
gramos por centímetro cúbico (un valor, por tanto, muy superior al del cuarzo cifrado en $2,65 \mathrm{~g} / \mathrm{cm}^{3}$ ).

- Difracción de rayos $X$ : el análisis fue realizado en el Difractómetro de los Servicios Comunes de Investigación de la Universidad de Oviedo partiendo de una cantidad mínima de polvo. Por ello fue necesaria la microdifracción sobre portamuestra de Silicio. La presencia de fuertes reflexiones, correspondientes a espaciados reticulares de 3,34 y 3,18 , demuestra que el hacha está formada mayoritarimente por cristales de cianita (distena).

Dado que la distena pura suele tener densidad un poco más alta que los valores aquí encontrados, cabe concluir que la ligera disminución de densidad viene conferida por la presencia de otros minerales tales como cuarzo y feldespato.

- Conclusión sobre la naturaleza de la pieza: se trata de un objeto elaborado a partir de masas de cianita con impurezas muy localizadas de cuarzo, moscovita, turmalina y feldespato.

- Conclusión sobre su procedencia: dado que la cianita de estas características es un material geológicamente muy raro en España, y en general en la Península Ibérica, la identificación de la naturaleza del arma de Marabiu aportó excelentes expectativas sobre su procedencia material. Queda descartada, en primer lugar, la procedencia local de la roca, sin duda alógena en el territorio de laAsturias central donde no existen los materiales aludidos ni minerales metamórficos; tampoco en el resto de la región existe la cianita ya que las condiciones de presión y temperatura del metamorfismo local no fueron suficientemente elevadas para que aquella se formara.

Al ser la cianita una variedad de silicato de aluminio (cómo la andalucita y la sillimanita) originada bajo presiones muy elevadas, aparece sólo en lugares muy concretos. En todo el Norte de España se observa esporádicamente en un cinturon metamórfico que va desde Vivero a Lugo y Sarria. Existe también en el norte de Portugal, pero dadas las características de la pieza de Marabiu creemos, con un altísimo grado de probabilidad, que provenga la pieza de otra zona metamórfica de alta presión, la situada entre Pino y Touro, localidades de la provincia de La Coruña, al norte del río Ulla y escasos 20 a $25 \mathrm{Km}$ al este de Santiago de Compostela. Tal precisión es fundamental y muy probable puesto que en Touro hay grandes masas de cianita, procedentes de pseudomorfismo de andalucita, que permiten elaborar objetos de tamaño medio a grande. Además, la semejanza de la cianita en bruto de
Touro con el material del arma de Marabiu es tan considerable, incluso en los detalles más finos, que no resulta arriesgada la hipótesis de que la zona metamórfica Pino-Touro fuera la zona original de procedencia de los instrumentos que presenten las mismas características de la pieza asturiana, En efecto, aquel área constituyó, desde antiguo hasta 1997, el enclave único de producción industrial de cianita en España, obtenida mediante el dragado y: lavado de aluviones.

Para abundar más en la hipótesis de procedencia se procedió también al análisis colorimétricẹ eưan: titativo comparado del ejemplar de Marabiu y de masas de cianita bien cristalizadas de Tóuro con idénticas características de visu. Fue utilizado un colorímetro digital Minolta CR-200, efectuándose cuarenta medidas puntuales en el arma y en la cianita de Touro que aportaron los valores medidos:

1- 1, que determina la intensidad de color entre dos extremos, $\mathrm{l}=0$ (color negro) y $\mathrm{l}=100$ (color blanco puro)

2- $a^{*}$, que mide la tendencia cromática entre valores de $\mathrm{a}^{*}$ negativos (colores verdes) y $\mathrm{a}^{*}$ positivos (colores rojos)

3- $b^{*}$, que mide la tendencia cromática entre valores de $b^{*}$ positivos (colores amarillos y $b^{*}$ negativos (colores azules).

El valor medio de intensidad de color (1) del hacha es: 44,32 $\pm 3,36$. El valor medio de la cianita de Touro es: $44,64 \pm 1,89$. Son, en consecuencia, prácticamente indistinguibles. Los tonos cromáticos de ambos materiales son asímismo casi idénticos. En la gráfica adjunta (Fig. 2) fueron proyectados todos los valores $\mathrm{a}^{*} \mathrm{y}^{*}$ de los puntos medidos en el hacha y en la cianita de Touro, así como sus rectas de

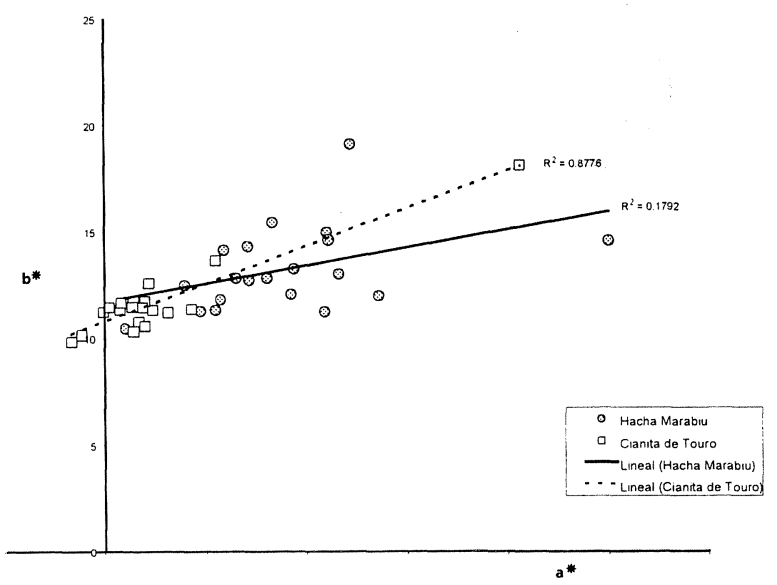

Fig. 2. Comparación entre los análisis del hacha de Marabiu y la cianita de Touro. 
correlación. Se aprecia claramente que la tonalidad en valores numéricos es prácticamente la misma, con una lígerísima tendencia del hacha hacia tonalidades más verdosas.

Cabe concluir, en suma, que son idénticos ambos materiales y, por ello, que con las mínimas probabilidades de error, el arma de Marabiu procede de Galicia, y concretamente del área coruñesa de Touro (Fig. 3).

\section{LAS HACHAS Y AZUELAS CON PERFORACIÓN VERTICAL DEL NOROESTE}

Caracteriza a este singular grupo de objetos del NO ibérico su falta de homogeneidad tipológica, hecho que habla de una cierta libertad en la confección de cada pieza partiendo de patrones genéricos más o menos compartidos, variedad en la que se precisan, empero, afinidades que apuntan a un ámbito de creación común (su naturaleza mineral suele ser reseñada con el genérico "roca plutóni$c a$ ”). En efecto, entre las piezas de doble frente activo conocidas responde casi cada una a un diseño diferente:

a) Perfil arqueado, filos verticales y amplios, y zona de ensanchamiento del objeto a la altura del orificio de enmangue: pieza coruñesa de SanAndrés de Meirama (Fábregas, 1988: VII, 2) (Fig. 4, 1). Un ejemplar semejante fue visto por Luengo (1974-75, 137) en el Museo Municipal de Santo Tirso, Portugal.

b) Desarrollo biapuntado de lados convexos, perforación bicónica y filos verticales cortos: sendos ejemplares del túmulo 1 de Monte Campelos, Lugo ( Rodríguez Casal, 1983) (Fig. 4, 3) y de un túmulo de tipología desconocida del lugar de Rabo de Lobo, ayuntamiento de Tordoia, La Coruña (Fábregas, 1991: 294,VIII) (Fig. 4, 2).

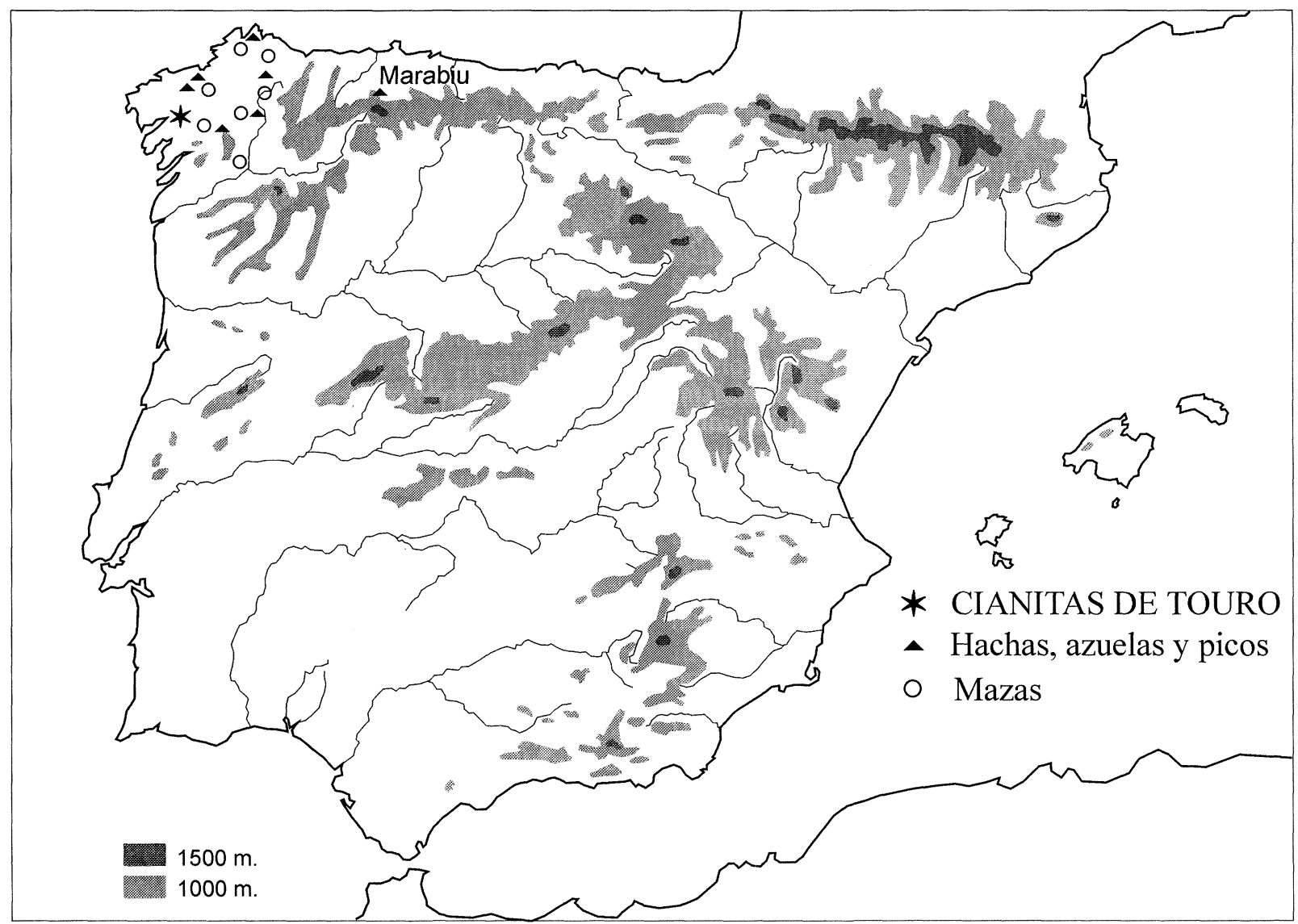

Fig 3. Distribución de los perforados gallegos y localización del de Marabiu (Asturias) y de su origen geológico en Touro, La Coruña (con la colaboración de J.L. Seoane).

T. P., 58, n. $^{\circ} 2,2001$ 

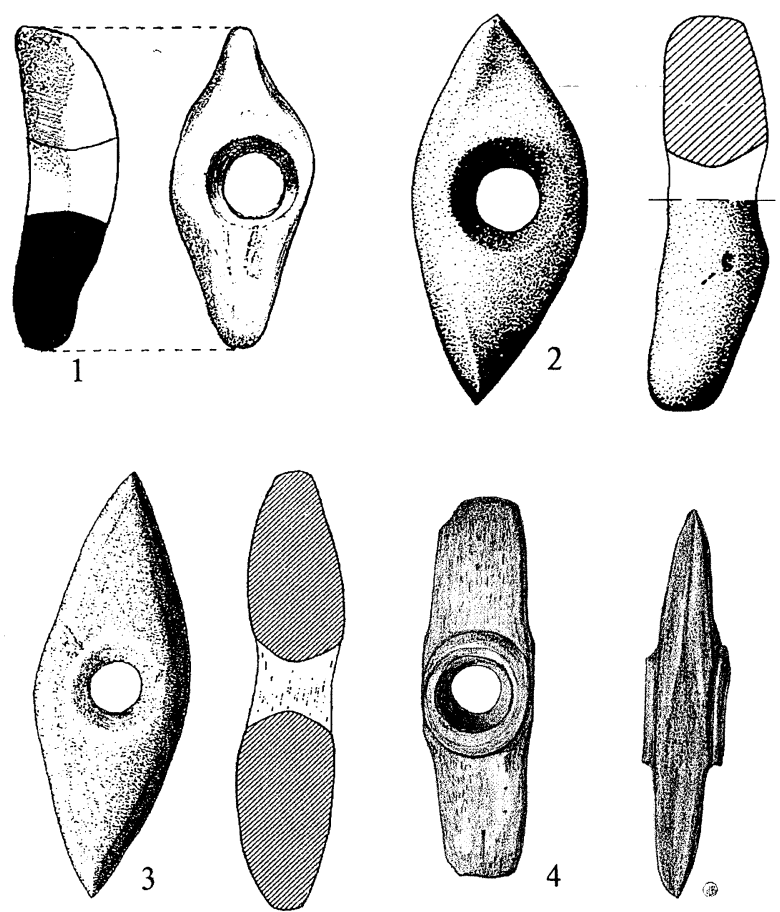

Fig. 4: 1, SanAndrés de Meirama (Luengo, 1974-1975); 2 , Rabo de Lobo (Fábregas, 1991); 3, Monte Campelos (Rodríguez Casal, 1983) y 4, Monte das Regas (según de Blas). A diferentes escalas.

c) Subelipsoide de filos horizontales amplios y, por tanto, sección longitudinal biapuntada: túmulo de Pago da Matela, Lugo (Luengo, 1974-1975: 131-133 y Fábregas, 1988: XXII, 3) (Fig. 5, A).

d) De filos horizontales y estrechos, lados convexos, perforación central bicónica y reborde o bocel en uno sólo de los inicios de agujero: túmulo de Veiga das Mámoas (Fábregas, 1983: 31-32 y Fábregas, 1988: XXVI, 2) (Fig. 6).

e) Subelipsoide de filos horizontales y anchos, ligero ensanchamiento central del cuerpo y reborde sobre ambas aperturas de la perforación bicónica: pieza de Monte das Regas, La Coruña (Maciñeira, 1947: lám V) (Fig. 4, 4).

f) Ensanchamiento a la altura del orificio, filos horizontales cortos y embotados, boceles de refuerzo del orificio en ambas caras: Marabiu, Asturias (Fig. 1).

En una clasificación funcionalista se podrían agrupar, tal como hiciera Fábregas, en las categorías de hacha doble las de San Andrés de Meirama y Monte Campelos 1, y probablemente la pieza aludida de Rabo de Lobo, y comodobles azuelas las de Pago da Matela, Veiga das Mámoas y Monte das Regas. Fue precisamente el ejemplar de este último lugar el que llevó a F. Maciñeira (1947: 56) a darle esa denominación instrumental. Por su parte la pieza de Marabiu, por los grosores y dimensiones de sus zonas activas, no puede ser incluida, automáticamente, entre las hachas o dobles azuelas; tal vez habría de catalogarse como pico doble. En esa posición, a medio camino entre un grupo y otro, resultan enigmáticas las fracturas de percusión que presenta en ambos extremos. Bien es cierto que, más allá del juego clasificatorio, el conjunto de estos objetos ofrece una estructura formal poco adecuada para su empleo como útiles. Todo parece sugerir, en cambio, como resaltaremos más adelante, un uso particular ajeno a las misiones encomendas a las más habituales hachas y azuelas en hojas de piedra pulimentada.

En general, atendiendo a la manipulación, apenas se ha valorado su modo de enmangue. Es evidente que la fijación de un astil a objetos de orificio bicónico plantea más dificultades que cuando el mismo es cilíndrico. La propuesta que ofrecemos gráficamente (Fig. 1) es razonable aunque, a la vez, implica una cierta fragilidad del astil, menguado en su grosor para ajustarse a las reducidas dimensiones del agujero. En todo caso, el encaje de cuñas entre las paredes del embudo superior y el cilindro del mango tiene su refrendo testimonial en el descubrimiento, reciente, de un hacha completa durante las excavaciones de 1999 en el yacimiento neolítico de Cham-Eslen en el suizo Zugersee, en el que los limos lacustres preservaron tanto el mango de madera como las cuñas, de asta de Cervus elaphus, que lo afirmaban en su extremo superior (GnepfHorisberger et alii, 2000).

Puede la fragilidad comentada, a là vez, denunciar el uso restringido de este tipo de artefactos cuyos mangos no soportarían la percusión reiterada, el golpeo frecuente propio de un instrumento, operen como azuela, hacha o maza. Resulta, además, un argumento indirecto para reconocer en nuestros perforados unos fines apartados de los meramente instrumentales; quizá un uso basado más en la dimensión simbólica que en su bondad mecánica.

\section{CONTEXTO ARQUEOLÓGICO Y CULTURAL (EXOTISMO O PRODUCCIÓN LOCAL)}

Comparten casi todas las piezas que conocemos un medio genérico de procedencia: las arquitecturas tumulares en principio incardinadas en el ámbito multiforme de la monumentalidad de raíz megalítica.

T. P., 58, n. ${ }^{\circ} 2,2001$ 

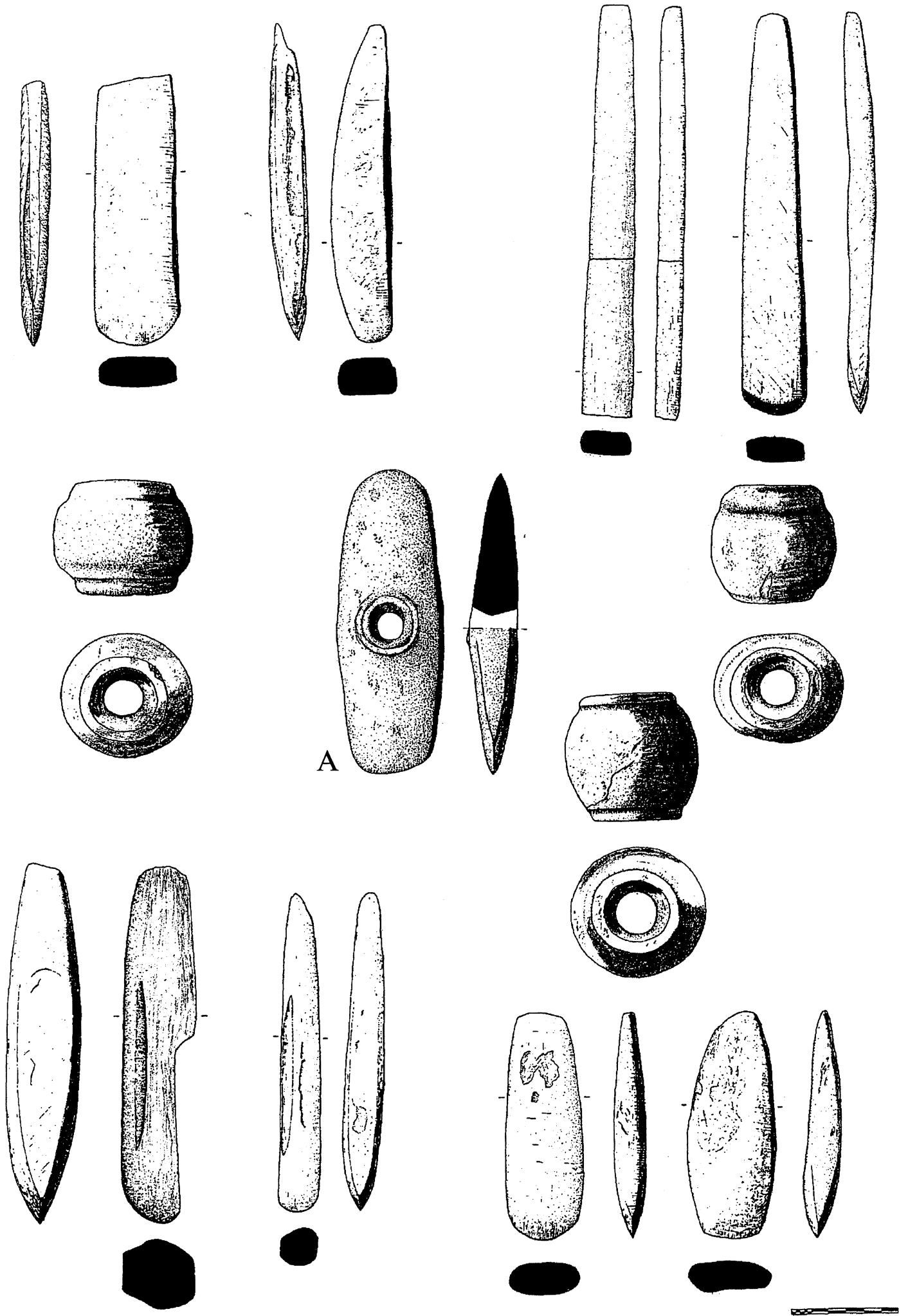

Fig. 5.Azuela doble, mazas y otros pulimentados de Pago da Matela (según Luengo, 1974-75 y retocados sobre Fábregas, 1988).

T. P., 58, n. $^{\circ} 2,2001$ 


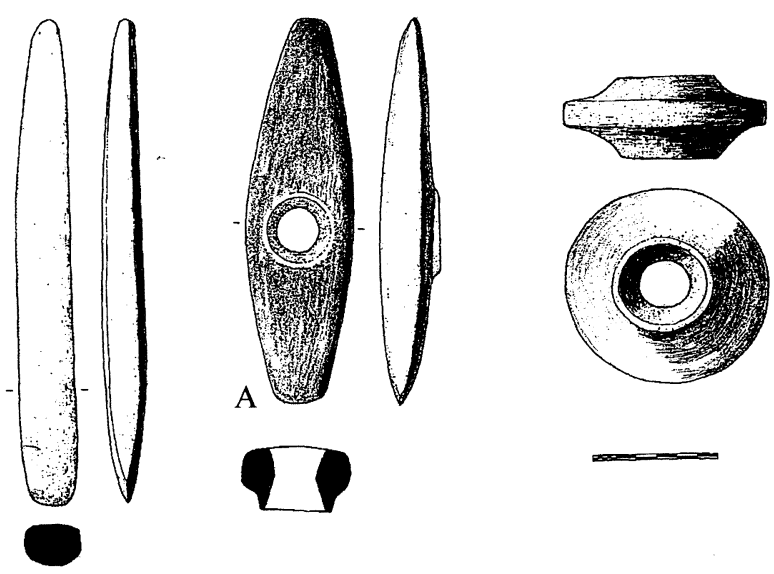

Fig 6. Veiga das Mámoas (retocado a partir de Fábregas 1988).

Si para la de SanAndrés de Meirama se apunta su origen en una probable construcción dolménica, dato que aunque impreciso no debe de ser desdeñado, en la de Pago da Matela el contexto es más incierto: un túmulo arrasado cuya estructura es, obviamente, desconocida. La doble azuela de Veiga das Mámoas, el propio topónimo alude de modo expreso a la presencia en el lugar de los montículos prehistóricos, fue hallada en una cámara a modo de cofre pétreo al que cerraba una cubierta monolítica.

La doble azuela de Monte das Regas apareció accidentalmente en 1916 "a flor de tierra", cerca de un arroyo, junto con un hacha neolítica, en palabras de F. Maciñeira quien ante la carencia de un contexto más claro supuso la procedencia de los materiales en un medio funerario dada la abundancia de los túmulos en las sierras inmediatas. Descubierta casi en superficie por un pastor no excluye tal circunstancia, a nuestro entender, la posibilidad razonable de que el suelo en cuestión correspondiera a algún sector de un túmulo inadvertido, tal vez por su grado de denudación, por el informante de Maciñeira.

Son sin duda más firmes las noticias aportadas por el túmulo lucense de Campelos, en el que la recuperación de los materiales hoy conservados se efectuó en el transcurso de la excavación de urgencia, subsiguiente a la destrucción parcial de un túmulo de dimensiones notables (diámetros de 20, 50 y $18,30 \mathrm{~m}$ ). El ajuar en causa se encontraba en una fosa excéntrica, de $2,70 \mathrm{~m}$ de largo y $1,50 \mathrm{~m}$ de profundidad, abierta tras la erección del túmulo, rellena de un sedimento rojizo aportado ex profeso para la confección de lo que se interpretó como probable enterramiento (Rodríguez Casal, 1983: 11).

Lógicamente, las condiciones contextuales no sólo se concretan en la naturaleza de los túmulos aludidos; adquieren cuando menos cierto valor indicativo los demás elementos asociados, integrantes del universo de las ofrendas rituales. Es esa reunión de informantes arqueológicos la que dibuja un episodio que tiempo atrás Vázquez Varela (1979) distinguiera como "horizonte Rechaba". Hay en tales asociaciones una perceptible reiteración de sus componentes. En Monte Campelos 1, además de la pieza de orificio, otras tres corresponden, en una catalogación funcional, a una azuela de fibrolita y dos cinceles de esquisto. En el túmulo de Pago da Matela el viático sepulcral recuperado fue notable: un hacha pulimentada de fibrolita, cinco láminas de azada, de esquisto, también de cuidado pulimento, un cincel de cuarcita y tres mazas de volumen toneliforme y perforación bicónica o bitroncopiramidal. Por último, la doble azuela de Veiga das Mámoas se asocia a un cincel de esquisto y a una maza en roca plutónica. En suma: mazas, hachas dobles y láminas de azada son materiales cuya asociación resulta segura (Fábregas, 1984: 154), mientras que el cuarto elemento a considerar, el cincel, tiene un ámbito de relación más amplio.

Ante la falta de una mayor robustez de la documentación disponible, se acepta en la actualidad el carácter tardío de los útiles-arma perforados, en un momento incierto del III milenio, acaso poco antes del 2600-2400 cal AC, en un episodio previo a la aparición campaniforme. Es por entonces cuando toman cuerpo nuevas modalidades sepulcrales, entre las que figuran los túmulos con cámaras rectangulares, los de constitución térrea carentes de una cámara ortostática, u otros soterrando estructuras apenas detalladas de las que sirve como referencia la fosa excéntrica de Monte Capelo 1 (Rodrígez Casal, 1983; Fábregas, 1994; Bello y Peña 1995: 107).

De una forma más atenta a los cambios operados en la ritualidad funeraria neolítica-calcolítica, la identidad de los perforados tal vez hallara sus raíces en ámbitos noreuropeos, acaso en el de los campaniformes cordados. En esa línea interpretativa, afinidades tipológicas e imprecisión en su uso acercarían las piezas bipolares del NO ibérico a los picos (spitzhauen) de los grupos con cerámicas de cuerdas del NO deAlemania, del mismo modo que las mazas gallegas encontrarían su parentela mejor dibujada en la "Cultura de las tumbas individuales" $\mathrm{y}$ en sus conexos grupos campaniformes del $\mathrm{N}$ de Alemania y Dinamarca, tal como nos propone recientemente Suárez Otero, entendiendo este autor 
que los perforados en causa deben incardinarse en un amplio fenómeno transformador igualmente detectable en Galicia por el hallazgo de algún campaniforme cordado.

Hay, desde luego, una cierta cercanía morfológica entre los spitzhauen germanos, en especial los del grupo B-1 de la clasificación debida a Brandt (1976: Abb. 5, 10-12), en la que se agrupan los tipos simétricos de lados convexos y orificio bicónico, con algunos de tales útiles de Galicia, en la misma medida en que no se puede hablar de semejanza entre ambas creaciones, ofreciendo a la véz atributos tipológicos que acusan netas diferencias.

El diálogo N-S de los cordados con la "implantación de una fenomenología ajena (en Galicia) al sustrato local", se explicaría por la existencia de inmigraciones nórdicas, único modo de entender las considerables "distancias geográficas para objetos formal y conceptualmente idénticos", produciéndose un radical cambio cultural "sobre bases ajenas al substrato local" (Suárez Otero, 1997: 2429 y $1998,142-142$ ).

La firmeza con que se presenta esta arriesgada hipótesis migracionista actualiza, si bien ahora con tonos de mayor trascendencia, la vieja idea del origen norcontinental de las hachas de combate gallegas (Martínez Santa-Olalla, 1946: 136; Mac White, 1951: 45-46). Cierto es que no podemos dejar de admitir, según señalábamos más atrás, en algunos de los útiles-arma gallegos un notable acento continental, quizá una cercanía morfológica en gran parte fortuita. Las azuelas dobles, por ejemplo, en su cuerpo alargado y otros rasgos característicos sintonizan con piezas de la misma calificación funcional, genérica, en ambientes arqueológicos danubianos, gozando de testimonios muy expresivos en la Alemania central, Baviera y Baja Alsacia (Jeuneusse, 1997: 90-91) filiados en la cultura de la cerámica de bandas final y reciente; por tanto en el NeolíticoAntiguo, a caballo de los milenios VI aV a.C. Sin embargo, las piezas centroeuropeas de sección longitudinal plano-convexa, a diferencia de las de Galicia, son con frecuencia de gran talla, de buena ejecución y probablemente inútiles para cualquier actividad mecánica, entre otras razones por la estrechez de la perforación de enmangue y la fragilidad de algunas de las rocas empleadas para su confección. No hay duda de que se trata de objetos de parada, hallados mayoritariamente en tumbas individuales que parecen anteceder en su valor simbólico, como atributos de estatus, a las hachas de combate del Neolítico reciente (Zapotocky, 1992).
Notemos, a la vez, un hecho de innegable peso: entre la cronología temprana de estos productos de la Europa central y la de los gallegos se abre una dilatada brecha temporal de 2500 años.

No cabría, pese a ello, marginar la supuesta génesis foránea en el NO ibérico y, en consecuencia, desatender tanto el itinerario continental de la propuesta inmigración como las huellas arqueológicas de la misma.

Quedaría descartado al respecto un tránsito continental, de acuerdo con lo que más adelante nos mostrará la valoración de los tipos de hachas geográficamente cercanos, los deAquitania, cuyos atributos discuerdan notablemente de los ibéricos. El único documento existente en el territorio extendido entre los hallazgos franceses y el ejemplar de Marabiu, en el cantábrico centro-occidental, es la conocida hacha de perforación cilíndrica y desarrollado filo vertical procedente del megalito guipuzcoano de Balenkaleku. De su probable ascendencia bretóna habló ya hace decenios Bosch Gimpera (1932: 212). Su localización en el istmo peninsular no es extraña, del mismo modo que tampoco deberán serlo otros productos foráneos como los campaniformes cordados si bien presentes de forma extraordinariamente discreta en el territorio vasco (Armendáriz, 1988 y Alday Ruiz, 1996: 110-111).

En todo caso no está la pieza guipuzcoana físicamente alejada de regiones en las que los hallazgos de esa naturaleza son relativamente frecuentes, desde Las Landas hasta la Gironde y la Charente, territorio en el que se localizan tanto las llamadas hachas-martillo, como las de abultamiento a la altura del orificio o las muy características bipennes simétricas (Coffyn 1962; Coffyn y Gachina, 1969). Tal vez, como mera anécdota, pudiéramos recoger aquí la cercanía formal, en su simplicidad y rareza numérica, entre una pieza de la Charente Maritime, la de Saint- Eugene y la gallega de San Andrés de Meirama, o el relativo parecido entre la deVeiga dos Mouros y la pieza, con reborde en un orificio solamente bosquejado, de la Terre des Pots, de la antedicha región francesa (Gachina et alii, 1975: fig 4: 1 y 2), objeto que no deja, a la vez, de recordarnos las dobles azuelas germanas ya consideradas.

La estima de los caminos marítimos, nunca desdeñable en general, se nos antoja mucho menos verosímil si atendemos a la localización de los perforados de Galicia, en su mayoría de las comarcas interiores de la región, y mayoritariamente ajenos al territorio costero, si bien extraídos de túmulos ubicados en un escalón topográfico por debajo de 
los 500 metros de altitud, espacio contrastado con el más característico, en el mismo ámbito físico, en el que se produjo la instalación de los megalitos clásicos (Fábregas, 1992: 106). Los vínculos entre ese marco de baja altitud y la mayor aptitud del mismo para las tareas agrícolas no dejan de animar la sugerencia de una cierta relación entre esa actividad productiva, la bondad de las cosechas, y el distinguido utillaje perforado que se depositaba en los túmulos, arquitecturas en buena medida desviadas de la ortodoxia dolménica.

En cuanto a otras huellas arqueológicas en el NO de los supuestos "nuevos ocupantes" su repertorio resulta de muy difícil identificación. La vaga, y de desigual reparto espacial, documentación útil refleja el probable incremento, desde inicios del III milenio a.C., del territorio habitado y una más dibujada presencia en el mismo de aquellos materiales que señalan la inversión en el equipamiento doméstico (cerámicas, utillaje de piedra, primera metalistería), acaso como síntoma de un mayor sedentarismo vinculado a mejoras en los rendimientos agropecuarios. En ese ambiente son desiguales las diversas circunstancias comarcales, algunas con una mayor receptividad de pautas culturales y técnicas de origen ibérico meridional; otras, en cambio, como las tierras del interior, más refractarias a los estímulos foráneos. No obstante, un afán en mayor o menor medida compartido por unas y otras es el de la posesión de materiales prestigiados, a veces de importación, que propician el protagonismo de los grupos beneficiarios de una posición de privilegio en los circuitos de distribución de las mercaderías más valoradas. En este cuadro cultural lo que se preconiza no es, precisamente, la arribada de nuevos contingentes étnicos, si no el peso de la capacidad de autotransformación de las poblaciones locales.

En la hipotética reestructuración social autóctona que se iría operando a lo largo del milenio señalado, la novedad de los primeros poblados fortificados en el inmediato norte de Portugal tendría su correlato en los hábitats instalados en posiciones de dominio territorial surgidos en el sur de Galicia, quizá como reflejo de un paisaje social vertebrado en diferentes estratos de solvencia material, capaces algunos de tales de imponer o resaltar sus criterios particulares y modos de conducta.

Esta visión panorámica (Fábregas y Ruiz-Gálvez, 1997), aquí tan sólo bosquejada, parte de una situación material nacida de la diversidad e intensidad de la producción alimenticia, animada ésta por una agricultura de cierto empuje y por una cabaña ganadera en la que los bovinos habrían jugado un importante papel; visión inspirada en un registro informativo sugerente aunque todavía débil. Es también habitual en ese contexto la presencia de ciertas materias primas, como la variscita o el sílex, de segura importación extrarregional. Si la variscita se asocia al adorno personal, el sílex, básicamente usado en las puntas de flecha, alude a la dualidad caza-guerra y, a la exaltación del varón y a la belicosidad asociada a la disputa de espacios y áreas de aprovisionamiento.

En el ambiente de cambio cultural columbrado, de modificación de los patrones de vivienda y de subsistencia, de maduración de papeles sociales diferenciados en los que se percibe la concreción de posiciones jerárquicas, es donde adquieren sentido tanto la variedad sepulcral del tercer milenio como el equipo funerario tipificado por las hachas, azuelas y mazas con perforación vertical que aquí nos reclaman.

Solamente, en suma, se podrían asimilar los perforados al elenco de manifestaciones arqueológicas de la cultura de los vasos cordados, sin omitir que ese complejo de culturas, de relativa similitud entre el Dniester y el Rhin (Schutz, 1983: 114) y con su límite occidental en Alsacia, tiene como elemento diagnóstico dominante a las hachas de combate, muy distintas -en su neto contraste formal entre el talón y el filo además de otros rasgos tipológicos-, de las formas regulares y sumamente simétricas de nuestro Noroeste ibérico. Sin embargo, por encima de todo, las hachas perforadas en piedras duras y cuidadosamente pulidas calcolíticas habrían llegado a su cosmopolitismo gracias al ideario que las sustenta, a la mentalidad exaltadora de los atributos de la virilidad guerrera, y como símbolo del dominio y de la capacidad de conquista de las sociedades que erigen a tales hachas como emblemas.

Según señalábamos, tal soporte ideológico es perceptible en el NO, vinculado a diversas modalidades funerarias expresadas por pequeños túmulos en los que se nota la mudanza, cuyo motor inicial estaría ya actuando durante la plena madurez megalítica. No son necesarios, en síntesis, los movimientos de población si no la concreción de nuevas formas sociales. Lo acontecido en el sur de Escandinavia, donde el binomio vasos cordados-hachas de combate y su novedad cultural se habían venido interpretando como consecuencia de la irrupción de nuevos protagonistas históricos, se explica hoy, en 
clara oposición a la tradicional tesis migracionista, merced a la fortuna evolutiva de las sociedades neolíticas locales (Tilley, 1984: 121-142).

La existencia de élites entre las poblaciones megalíticas parece percibirse entre nosotros, al menos desde el IV milenio a.C., a través de muestras arqueológicas variadas y ciertos argumentos entre los que no es de importancia menor el que vislumbra el carácter restringido del uso de la tumbas colectivas (Delibes, 1995: 79-83; Blas Cortina, 1997: 319-322).

La densidad demográfica por entonces en Galicia se induce del elevado número de túmulos que aun perviven (alrededor de dos mil inventariados, por ejemplo, en la provincia de Pontevedra, o más de setecientos en la de Lugo...) presentes, además, en todas las comarcas de su territorio (Rodríguez Casal, 1990: 53-72). Ciertamente, la estimación de un poblamiento de alguna densidad es sólo genérica, sin posible base estadística o cuantitativa que sabemos inalcanzable (Andrés Rupérez, 1998: 200202). Pese a ello, el abultado inventario de los vestigios tumulares nos deja creer en la existencia de una masa crítica social, organizada en una densa trama socioeconómica en la que las actividades rituales habrían cumplido una importante misión. Los mensajes transmitidos por el repertorio arqueológico parecen denunciar el paso de los linajes megalíticos a una fase posterior de segregación de individualidades, de distinción de personajes notables en torno a los cuales, sus símbolos y sepulcros, se iría tejiendo la nueva solidaridad comunitaria.

Aunque en los ácidos suelos de Galicia no pervivan los esqueletos, todo parece apuntar, en los túmulos a los que se vinculan los pulimentados con pếferación, a un destino fúnebre individual, ya distanciados del siempre relativo colectivismo sepulcral asignado a las tumbas de sus antecesores. ofis?

\section{ALGUNAS CONSIDERACIONES SOBRE LA DIVERSIDAD Y SENTIDO DE LOS PERFORADOS CONTINENTALES}

Es un hecho bien conocido que a escala continental las hachas de piedra de agujero transversal, siempre de pulimento cuidadísimo, constituyen una constante en la que, sin embargo, la variedad tipológica y los distintos medios geográficos, culturales y cronológicos denuncian una realidad multiforme que no puede ser explicada unívocamente y, menos aún, como fruto exclusivo de un axial sus- trato histórico actuante a lo largo de un tiempo muy dilatado.

Nos consta que ya en elV milenio a.C., en ambientes calcolíticos tempranos como el reflejado en el extraordinario cementerio búlgaro de Varna, gozaban de alto aprecio las hachas perforadas de enmangue vertical, depositadas en inhumaciones individuales de gran riqueza, sepulcros de personas sin duda notables, si no francamente poderosas hasta el punto de que algunas fueran calificadas de "tumbas principescas" (Renfrew, 1978; Demoule y Lichardus, 1989).

Estas hachas en rocas claramente seleccionadas, objetos distinguibles de las variadas modalidades de hachas, azuelas, escoplos pulimentados con los que se atendían las labores cotidianas, esas singulares "hachas de combate" fueron atributos destacados de la llamada colonización indoeuropea de Europa. Aquel proceso de expansión étnica, tal como lo recreara M. Gimbutas (1997: 269-280), arrancaría hacia 4400-4200AC, momento en el que los rasgos detectables de la cultura Kurgan se materializan en las costas del Mar Negro, O. de Ucrania, Rumanía y Bulgaria. En cualquier caso, remitiéndonos en exclusiva a las hachas y mazas perforadas, es incuestionable su normalidad arqueológica en el área carpática desde elV milenio a.C., muy en especial en yacimientos de la cultura Precucuteni, hasta mediados del IV, y en la de $\mathrm{Cu}$ cuteni-Tripolje ya afines del mismo milenio (Manescu-Bilcu, 1993).

Entre 3400 y 3200 AC acontecería, siguiendo de nuevo a Gimbutas, una segunda oleada transformadora de la vieja Europa bajo el caudal renovador del pueblo patriarcal-pastoril de las estepas. Cuajarían por entonces nuevas culturas tanto en la Europa nórdica como en la central, nacidas de la mixtura de los recién llegados y el sustrato indígena. Ese desbordado flujo "indoeuropeizador" actuaría en el orden social, sustituyendo las estructuras matriarcales, igualitarias, por otras clasistas, patrilineales. Sería tal el ambiente en el que fueron erigidos los primeros poblados fortificados, incrementándose el peso de la actividad ganadera, aceptada la metalurgia y, ya en el ámbito espiritual, verificándose cambios radicales con la exaltación del varón guerrero. La infiltración, del 3000 al 2500 cal AC durante el período de las ánforas globulares, alcanzaría a Holanda, Dinamarca, sur de Escandinavia, este de Irlanda y NE de Europa. Fue el tiempo de maduración de lo que en las síntesis prehistóricas se conoce como "cultura del hacha de combate". 
El discurso unívoco y generalizador de Gimbutas ofrece, inevitablemente en su intención de definir un modelo histórico aplicado desde el Mar Negro hasta elAtlántico, numerosos flancos vulnerables, algunos ya señalados y otros nada desdeñables como el que los poblados protegidos por sistemas poliorcéticos diversos existían ya en la Europa occidental desde el NeolíticoAntiguo, por tanto mucho antes de la supuesta segunda fase indoeuropea. Igualmente, el hecho de que las gentes de la "cerámica cordada" fueran con frecuencia sedentarias, dependientes de una economía de base agropecuaria, rebaja notablemente la imagen pretendida de una sociedad de guerreros en continua migración (Renfrew, 1990: 79-87).

En el mosaico cultural de la prehistoria neolítica avanzada europea no deja de mostrarse, sin embargo, como un rasgo llamativo desde el IV milenio AC, la reiteración de las hachas perforadas, a menudo como viático mortuorio de varones adultos, acaso jerarcas en sus respectivas comunidades. En el registro arqueológico de los grupos de la cerámica cordada y TRB del III milenio destacan las hachas de combate entre los símbolos de distinción social más poderosos, desde Alsacia y este de Suiza hasta los ríos Movska y Dniester; desde Hungría a la Suecia central y sur de Finlandia (Whittle, 1985: 207-287; Schutz, 1983: 114).

Ya en el tránsito al occidente europeo las cuidadas hachas perforadas, de una elaboración bien distinta de las empleadas en el trabajo, aparecen en variadas culturas a partir de los milenios $V$ y IVAC como ocurre en las helvéticas de Cortaillod, Egolzwiller, al principio con diseños de perfiles regulares y simples; después, en versiones más elaboradas hasta imitar prototipos de cobre, en la cultura de Pfyner, ya a mediados del milenio, o también en contextos de la Schnurkeramische, entre el 29002600 a.C. (Winiger, 1981). A su vez en Italia, las de combate suelen ser novedades de la Edad del Cobre, aunque las hachas martillo y las cabezas de maza habían sido producidas autónomamente por algunos grupos neolíticos, en particular por los autores de la cultura de Ripoli (Renfrew, 1979: 240-241).

A occidente, las hachas de combate, dobles de filo vertical, se vinculan todavía en Bélgica al campaniforme tipo Belluwe, hacia 1900-1700 a.C. (Harrison, 1986: 22-23), al igual que en el Bajo Rhin en formas asimétricas y de talón estrangulado lo hacen con vasos también campaniformes de las variedades $\mathrm{AOO}$ y marítimos, depositados en túmulos a fines del III milenio (Lanting y Walls,
1976: 16-36; Walls, 1984: 23-26). Esa pauta es asimismo perceptible en las islas británicas con hachas-martillo muy sumarias, de tendencia cordiforme, probablemente introducidas por los campaniformes AOC de filiación continental (Clarke, 1970: vol 1: 63 y vol 2: 374, 384, 398; Case, 1984: 45) pero no demasiado próximas, tipológicamente, a los ejemplares holandeses. Destaquemos ya, de paso, que los diferentes perforados occidentales aludidos discuerdan claramente de los que estudiamos en el NO Ibérico. No cabe ocultar, además, el hecho de que el complejo cultural cordado en que se incardinan las hachas de combate no supera hacia el SO europeo la vertiente francesa del Jura, aunque el momento histórico sí parece caracterizarse por el trasiego de gentes y, desde luego, de ideas y técnicas a larga distancia (Petrequin y Petrequin, 1988: 198-199).

Hay en la Europa occidental, en suma, bajo la aparente homogeneidad de las hachas de combate del Calcolítico tardío, una subyacente generalización previa de los útiles-arma perforados. Diferenciar los productos de ambas fases es complicado por carecer la mayoría de los testimonios de un contexto arqueológico nítido. El camino danubiano, la aceptación del viaje de este a oeste de los más antiguos modelos no deja de ser, pese a todo, un acontecimiento aceptado (Bailloud, 1971: 349-351; Gnep et alii, 2000). A tal respecto es ilustrativo el caso francés. Mientras que en Alsacia y Lorena ya fueron comunes las hachas- martillo cordiformes durante el Neolítico Medio, con algún ejemplar de rasgos danubianos presente incluso en Normandía (Edeine y Lefebvre, 1969), los tipos más modernos, también de marcado acento germano, se asocian a los tardíos ambientes campaniformes y cordados (Thévenin, 1976). Frecuentes también los perforados en la Cuenca de Paris, serán en particular las $b i$ pennes, a veces naviformes, el referente normal de la región. Concentradas en el SO del territorio parecen atestiguar la penetración de tipos occidentales, bretones, a través del Loira, acaso siguiendo el mismo itinerario que otros productos en circulación como los apreciados sílex del Grand-Pressigny (Bailloud, 1971: 351).

Ciertamente, las hachas de combate bretonas, fabricadas en hornbledita tipo $\mathrm{C}$, siempre hachas d'apparat, características de la costa meridional de Armórica y regiones cercanas, propagadas a la cuenca baja del Garona, Somme y Países Bajos por el valor comercial de las rocas armoricanas (Giot, 1979: 369-370), ilustran la importancia del trasie- 
go de productos prestigiados. Son así mismo testimonios notables los pulimentados en metadolerita de tipoA procedentes de las canteras de Plussulien cuya demanda, nacida en elV milenio AC, alcanza hasta el III llegando a competir con los primeras hachas de cobre (Le Roux, 1999: 210-216). De las naviformes bretonas viaja, insistimos, algún ejemplar hasta Las Landas, límite meridional de su dispersión (Roussot-Larroque, 1976: 344-345).

Si algo resulta útil en el recorrido que se acaba de efectuar es la perspectiva panorámica del universo de los perforados, fenómeno de tanta amplitud espacial como cronológica. Hay, además, un rasgo técnico compartido por la mayoría: el ultrapulimento fruto de una considerable inversión de trabajo; un hecho que se torna, más allá de la estima de la mera belleza, en un verdadero atributo cultural (Petrequin et alii, 1997: 141).

En fin, el fenómeno de los perforados resulta, pese a su amplitud, genéricamente ajeno al ámbito peninsular. Los ejemplares concentrados en el extremo NO de Iberia parecen entonces responder a la recepción de ideas continentales y quizá, episódicamente, incluso de alguna de las hachas foráneas que materializaban aquel flujo mental. Proximidad tipológica aparte, a veces meramente azarosa, los modelos gallegos deben ser vistos como interpretaciones locales de un elementod'apparat, de pompa y ostentación.Apuntémos un hecho de interés: la personalidad de los perforados gallegos, con formas propias, no es exclusiva en la periferia atlántica de Europa; también en Irlanda, igualmente en los márgenes de los circuitos culturales del centro-occidente europeo, surgen hachas de combate singulares, entre las que ciertos modelos tardíos, en el medio cultural de las Food vessel urns, exhiben su heterodoxia con respecto a la tipología imperante en el dominio continental (Apsimon, 1969; Cowie, 1978: fig. 29).

Es aplicable el mismo argumento a las mazas subesféricas galaicas, para las que los supuestos prototipos mediterráneos resultan lejanos tanto física como formalmente si se valoran como pruebas en contra las mazas pétreas del Neolítico Reciente egeo (Treuil, 1983: 181-182), a las que se asimilan los tipos calcolíticos de la más occidental isla de Sicilia (Tusa, 1983: 202-204). En el improbable aliento meridional de las mazas gallegas se han señalado ciertos objetos esféricos, también perforados transversalmente, a los que se ubica en el $\mathrm{E}$ neolítico de Portugal (Alburquere y Veiga, 1967). Nada, ni en la forma, ni en el tamaño, parece apo- yar tal supuesto. Tampoco la búsqueda de analogías en el noroccidente europeo resulta demasiado pertinente. Es cierto que las mazas menudean en los viáticos sepulcrales del, por otra parte muy temprano, Neolítico Antiguo en el alto Danubio; ajuares de considerable riqueza y de filiación masculina. Pero tales Scheibenkeule o Keulenkopf, en la terminología alemana, son en su mayoría piezas de perfil oval, redondo o cuadrangular, y de volumen aplanado (Jeunesse, 1997: 88-89). Sólo un caso gallego ofrece afinidad con las mazas del Danubio superior: un ejemplar aplanado y subcuadrangular conservado en el Museo de la Coruña (Luengo, 1974-1975: lám. IV, 2 y fig. 2, 6). Señalemos empero que su morfología es tan ambigua que no necesita de inspiración foránea. Por otro lado, la apertura bipolar del orificio le otorga a éste el formato característico de las mazas, dobles azuelas, etc, de Galicia.

Tampoco, retornando a los ejemplares ovoides, son productos habituales en el territorio francés. La parquedad de su catálogo, señalada hace ya más de noventa años (Dechelette, 1908: 518-519), sigue todavía vigente. No cabría imaginar, en consecuencia, el influjo de tipos franceses en los singulares modelos cuajados en el noroccidente ibérico.

La escasa utilidad para fines mecánicos o productivos de los perforados gallegos anima a situarlos también en el universo simbólico, tal vez en su cometido de insignias de dignidad, de señales de autoridad. Objetos de esta naturaleza pueden corresponder con preferencia a varones ancianos, hombres que habrían ocupado posiciones destacadas tanto en el control de los recursos económicos como en la guerra.

Cuenta esta última hipótesis, la del arma-útilsímbolo, con un cierto apoyo documental en el hallazgo ya aludido del hacha enmangada del Zugersee suizo. El astil de madera conservado no sólo alcanza una medida llamativa por su exceso: 1,20 metros de largo; ofrece además una cuidadosa decoración a base de corteza de abedul recortada a punzón componiendo una grata teoría geométrica de losanges. Es de entender que la idea del cetro aflore ante la notabilidad de este testimonio helvético. Los antecedentes de tal simbolismo son mucho más nítidos al final del corredor danubiano. Algunas tumbas del celebrado cementerio de Varna, como la excepcional n. ${ }^{\circ} 43$, contenían hachasmartillo marmóreas fijadas en un mango de madera recubierto por láminas de oro. Inhumaciones individuales, ajuares riquísimos y hachas enmangadas 
sobre el esqueleto dan solidez a la conjetura razonable de la simbolización del poder (Teodorova, 1978: 69). Nos consta, además, que la sepultura 43 encerraba los despojos fúnebres de un varón de 40 a 50 años. Su retrato, reconstruido sobre el cráneo siguiendo el método de Guerasimov, sería el de un hombre fuerte, "evocando al jefe poderoso y sabio" (VV. AA., 1989: 163-164). Hubo de ser, en cualquier caso, un individuo maduro, ya próximo a la ancianidad, longevo en una época en la que según los datos antropológicos la esperanza de vida se situaría entre los 25 y 32 años. Cetro-varón-anciano parece así un trinomio bien establecido.

Pese a lo dicho, y ampliando el contenido ideológico de lo reseñado, cabe recordar que más a occidente, de nuevo en el alto Danubio, aquellos atributos de poder y prestigio figuran igualmente en los ajuares mortuorios de inhumaciones infantiles rubanenses, lo que deja vislumbrar su pertenencia a élites sociales cuyos privilegios irían transmitiendose, heredados, de generación en generación (Jeunesse, 1997: 116-117).

Cuando los yacimientos arqueológicos foráneos, con esqueletos bien conservados, arrojan informes tan elocuentes no es fácil, una vez más, reprimir el lamento ante la acidez de los suelos gallegos y su implacable poder destructivo.

\section{RECAPITULACIÓN Y ALGUNA NOTA POSTRERA}

La presencia de un perforado en Marabiu, en las montañas de laAsturias central, se debe,tras su estudio petrológico, a una importación prehistórica desde las tierras del occidente de Galicia. Su localización viene a corroborar los lazos existentes a lo largo del Neolítico, en su versión megalítica, entre Asturias y Galicia (Blas Cortina, 1983 y 1997).

El foco de perforados galaico, definido en distintas versiones tipológicas, es de innegable personalidad y no debe su existencia a la arribada directa y reiterada de productos del noroccidente europeo, tratándose, por el contrario, de la versión local de objetos destinados a la simbolización del poder y dignidad de ciertos individuos o linajes. Es más verosímil que el fermento autóctono enraizara en el ideario difundido con las mudanzas neolíticas actuantes, a lo largo de un largo proceso milenario, entre el mar Negro y el Atlántico, ideario aclimatado caleidoscópicamente en ambientes geográficos y culturales muy diversos.
La raigambre noroccidental de los perforados, no mediterránea, parece clara por discretas analogías formales, y en particular por rasgos de innegable afinidad entre lo observado en Galicia y en ciertas áreas continentales: el contexto sepulcral en ambas regiones de las piezas mejor documentadas $\mathrm{y}$, especialmente, por la llamativa asociación en las tumbas ibéricas del binomio doble azuela-maza, dualidad firme tanto en el NE de Francia como en el O deAlemania.

El fenómeno de los perforados no prende en Iberia y la excepcionalidad del foco gallego debe ser explicada en términos de aclimatación, por su idoneidad, en un momento crucial de cambio en las sociedades megalíticas locales. La tentación de una hipótesis orientada a la actividad de grupos continentales inmigrantes en nuestro NO es sin duda sugerente, pero carece de la imprescindible apoyatura documental que la haga verosímil.

La singularidad de la circulación de un determinado ideario y de su arraigo en el Finisterre meridional europeo, sin un camino franco-cantábrico reconocible, no excluye la hipótesis de las navegaciones episódicas, aunque ya en tiempos muy anteriores la fijación aparentemente desconectada con sus orígenes probables de ideas y usos continentales ofrezca analogías con el fenómeno de los perforados. Nos referimos, como simple ilustración, a la innegable similitud en manifestaciones instrumentales, mobiliares y artísticas (técnica e iconografía de ciertos conjuntos de arte rupestre) entre los artífices del Magdaleniense del cantábrico central (oriente de Asturias y occidente de Cantabria) y el mismo ciclo cultural del SO francés o de la región pirenaica del Ariége, sin claros testimonios de apoyo en el ámbito geográfico que separa ambas regiones.

Los perforados gallegos se vinculan además a un territorio en el que la calidad de algunas de sus formaciones rocosas nos podrían hacer pensar en una producción solicitada desde otras comarcas. Paralelamente, los ennoblecidos poseedores de los perforados deberían de disfrutar de los réditos de la comercialización de tales piedras. Obviamente, la consideración de esta propuesta o su desestima requieren la futura intensificación de los estudios petrográficos, tanto del instrumental galaico como del de las regiones vecinas.

El que los perforados gallegos provengan de túmulos situados en altitudes de menos de 500 metros sobre el nivel del mar permite considerar, además, la importancia en aquellos espacios de una producción agrícola capaz de generar excedentes intercam- 
biables por productos importados. Tal vez, entre otros, intervinieran ciertas materias tan estimadas como imprescindibles; acaso la sal que podría ser en parte recibida desde las comarcas costeras. Es sabido, tanto en sociedades primitivas como en las históricas, que del mercadeo del "oro blanco", del control de su distribución, se suelen derivar grandes beneficios no, en exclusiva, para las gentes instaladas en las áreas de producción, si no también para los intermediarios operando en comarcas ya alejadas de las salinas. Dos notables ejemplos del Neolítico europeo ilustran las plusvalías generadas por la sal. Por un lado el esplendor de los primeros metalúrgicos delV milenio AC en Varna, sobre el Mar Negro; por otro el de los autores del potente megalitismo bretón de Morbihan, sobre la costa atlántica, en el extremo opuesto del continente. Entre ambos focos de innovación cultural no cabe establecer una relación difusionista primaria, lineal, en sentido este-oeste; al contrario, la expansión de muchos de los factores técnicos o mentales tendría lugar por contigüidad, de hito en hito, circulando entre sociedades vecinas y con ciclos de actuación cada vez mejor identificados (Petrequin et alii, 1997: 145-147; Bailloud et alii, 1995: 583-597). El prestigio de las hachas perforadas en Varna y el de las grandes hojas de jadeita alpina en el caso de Bretaña, testimonian la expansión continental del valor simbólico de aquellas armas-instrumento excepcionales.

Siempre que los diferentes perforados galaicos disponen de contexto se trata de túmulos no dolménicos, acogiendo cofres pétreos o fosas, a veces en ubicaciones marginales en el montículo. Todo parece apuntar a tumbas individuales, a la vez que esas hachas dobles, azuelas dobles y mazas subesféricas se acomodan a la idea del cetro como atributo de notoriedad, asociado al poder material o a la sabiduría de los personajes enterrados. La reunión de varias de esas insignias en un mismo túmulo plantea la pregunta de si fue el túmulo la tumba de uno o más notables. Sin respuesta segura en la ausencia del testimonio de los propios esqueletos, la hipótesis del sepulcro individual no debe tacharse de arbitraria. En Varna, por ejemplo, son varias las hachas-cetro con un único cadáver en la tumba 43. En fechas mucho más recientes, del II milenioAC, y en el opuesto occidente europeo, mientras que el famoso y principesco Bush Barrow aporta un cetro único (Ashbee, 1960: 67-77), un túmulo bretón del bosque de Carnöet, también sepulcro individual y no muy distanciado temporalmente de aquél, aco- ge varias armas de prestigio (Briard y Mohen, 1974). Es probable que en este último nos hallemos ante una reiteración material propia de un tiempo en el que el poder individual estaría asociado tanto al control como al uso de objetos de prestigio (Clarke et alii, 1985: 87 y ss., 114 y 115).

En fin, el fenómeno de los perforados galaicos parece debido a las transformaciones sociales que en la primera mitad del III milenio a.C. iban produciéndose en el NO ibérico, afectando a la ritualidad funeraria y a los símbolos movilizados por la misma. Pasado o todavía en decadencia el esplendor de los sepulcros megalíticos, los nuevos túmulos y la documentación arqueológica que se les asocia hablan, en su aparente discreción, más de diversidad que de rutina, reafirmando la impresión de que lo multiforme, lo opuesto a la monotonía, es síntoma de una aceptable pujanza cultural. Cada episodio de cambio, de desarrollo, requiere la creación de nuevos y bien reconocibles símbolos de estatus, entre ellos los fácilmente portables como los perforados de Galicia, siempre en rocas selectas, que acabamos de considerar.

\section{AGRADECIMIENTOS}

Queremos expresar nuestro agradecimiento por su colaboración infográfica a José Luis Seoane (Dpto. de Geografía) y al prof. Fernández-Tresguerres, ambos de la Universidad de Oviedo.

\section{BIBLIOGRAFÍA}

ANDrÉs Rupérez, T. (1998): Colectivismo funerario neoeneolítico. Aproximación metodológica sobre datos de la cuenca alta y media del Ebro. Instituto "Fernando el Católico". Zaragoza.

Alburquerque e Castro, L. de y Veiga Ferreira, O. da (1967): "Acerca das peças circulares de pedra, com furaçao central bicónica, encontradas no Eneolítico de Portugal". Revista de Guimaraes, LXXVII: 103-108.

Alday Ruiz, A. (1996): El entramado campaniforme en el Pais Vasco. Los datos y el desarrollo del proceso histórico. Anejos de Veleia. Series maior 9. Instituto de Ciencias de la Antigüedad. Vitoria. Universidad del País Vasco.

Apsimon, A.M. (1969): "The Earlier Bronze Age in the North of Ireland". Ulster Journal of Archaeology, 32: 28-72.

ArmEndÁriz,A. (1988): "Vaso campaniforme de la cueva de Amalda II (Cestona, Guipúzcoa)”.Munibe, 40: 83-88.

T. P., 58, n. $^{\circ} 2,2001$ 
AshbeE, P. (1960): The Bronze Age round barrrow in Britain. London.

Bailloud, G. (1971): Le Néolithique dans le Bassin parisien. IIe sup. à Gallia-Préhistoire. CNRS. Paris.

Bailloud, G.; Boujot, C.; Cassen, S. y Le Roux, Ch.-T. (1995): Carnac. Les premières architectures de pierre. Caisse nationale des monuments historiques et des sites. CNRS. París.

Bello, J. Ma y PeÑA, A. de la (1995): Historia de Galicia. I. Galicia na Prehistoria. Via Láctea Editorial.

Blas Cortina, M.A. de (1973): "Un hacha de combate de tipo nórdico de Teverga (Asturias)". Ampurias, 33: 217-230.

- (1983): La Prehistoria reciente enAsturias. Fundación Pública de Cuevas y Yacimientos Prehistóricos deAsturias. Principado deAsturias. Consejería de Educación y Cultura. Oviedo.

- (1997): "Megalitos en la región cantábrica: una visión de conjunto". En A. Rodríguez Casal (ed.): O neolítico atlántico e as orixes do megalitismo. Actas do Coloquio Internacional U.I.S.P.P. Santiago de Compostela: 311-334.

Bosch GIMPERA, P. (1932): Etnologia de la península Ibèrica. Alpha. Barcelona.

BRANDT, K. H. (1976): "Derivate neolithischer Streitäxe im nordwestdeutschen Raum". Jahresschrift für Mitteldeutsch Vorgeschichte, 60: 263-284.

BRIARD, J. y MoHen, J.P. (1974): "Le tumulus de la forêt de Carnoët à Quimperlé (Finistère)". Antiquités Nationales, 6: 46-60.

CASE, H. (1984): "The Beaker Culture in Britain and Ireland". En J. Guilaine (dir): L'Age du Cuivre européen. Civilisations à vases campaniformes. Ed. CNRS. Paris: $38-57$.

Clarke, D.L. (1970): Beaker pottery of Great Britain. 2 . Cambridge University Press. Cambridge.

Clarke, D.V.; Cowie, T.G. y Foxom, A. (1985): Symbols of power at the time of Stonehenge. National Museum of Antiquities of Scotland. Edinburgh.

Coffyn, A. (1962): "Les instruments perforés du Musée de Libourne". Bulletin de la Société Préhistorique Française, LIX, 1-2: 35-42.

Coffyn, A. y GaChina, J. (1969): "Instruments perforés de la Charente-Maritime". Bulletin de la Société Préhistorique Française, 66 ( 2): 58-60.

Cowie, T.G. (1978): Bronze Age Fodd Vessel Urns. B.A.R. British series 55. Oxford.

DeChelette, J. (1908): Manuel d'Archéologie préhistorique celtique et gallo-romaine. I. Archeologie préhistorique. Paris.

DeliBes, G. (1995): “Ritos funerarios, demografía y estructura social entre las comunidades neolíticas de la submeseta norte". En R. Fábregas, F. Pérez y C. Fernández (eds.): Arqueoloxía da morte na Península Ibérica desde as orixes ata o medioevo. Excmo. Concello de Xinzo de Limia. Orense: 63-94.
Demouele, J.-P. y Lichardus, M. (1989): "Invention du metal et premiéres inégalités: la nécropole de Varna dans son contexte européen". Le premier or de l'Humanité en Bulgarie 5 e millènaire. Editions de la Réunion des musées nationaux. Paris: 38-44.

EDEINE (C.N.R.S.) y LeFEBVRE, G. (1969): "Hache-marteau de type danubien découverte dans le département de l'Orne". Bulletin de la Sociétè Préhistorique Française, 66, 1: 25-26.

FÁBREGAS, R. (1983): "Materiales líticos del Museo Provincial de Lugo. Precisiones sobre la fase final de la cultura megalítica del NO peninsular". Boletín do Museo Provincial de Lugo, I: 31-42.

- (1984): "La industria de piedra pulida en las sepulturas megalíticas de Galicia". Trabajos de Prehistoria, 41: 129-163.

- (1991): Megalitismo en el noroeste de la península Ibérica. Tipología y secuencia de los materiales líticos. Aula abierta, 58. UNED. Madrid.

- (1994): "El túmulo de Bedro Vello: cuestiones acerca del megalítico final de la Galicia interior". Actas do Seminario "O megalitismo no Centro de Portugal" (Mangualde, 1992): 103-109. Viseu.

FÁBREGAS, R. y FuENTE, F. de la (1988): Aproximación a la cultura material del megalitismo gallego: la industria lítica pulimentada y el material cerámico. Arqueohistoria, 2. Universidad de Santiago de Compostela. Santiago de Compostela.

FÁbregas, R. y Ruiz-GÁlvez, M.L. (1997): “El Noroeste de la península Ibérica en el IIIer y II $^{\circ}$ milenios: propuestas para una síntesis". Saguntum: Papeles del Laboratorio de Arqueología de Valencia, 30: 191-216.

GaChinA, J.; Gómez, J. y Coffyn, A. (1975): "Supplément à l'inventaire des instruments perforés pour les départements de Charente, Charente-Maritime et Gironde". B. S. P. F., 72: 368-378.

Gimbutas, M. (1997): Kurgan Culture and the Indoeuropeanization of Europe. Selected articles from 1952 to 1993. (M. Robbins Dexter y Karlene Jones-Bley, ed.). Journal of Indo-European Studies Monograph, 18. Washington, D.C.

Grot, J.P. (1979): "La vie au néolithique". En P.R. Giot, J. L'Helgouach y J.L. Monnier: Préhistoire de la Bretagne. Rennes. Ouest France: 323-373.

Gnepf-Horisberger, V.; Gruss-Klee, E. y Hochuli, S. (2000): "Eine einzigartige Doppelaxt aus dem Zugersee". Archäeologie der Schweiz, 23: 2-9.

Harrison, R. (1986): L'Age du Cuivre. La civilisation du vase campaniforme. Ed. Errance. Paris.

Jeunesse, C. (1997): Pratiques funéraires au néolithique ancien. Sépultures et nécropoles danubiennes 55004900 av. J.-C. Ed. Errance. Paris.

Lanting, J. N. y Walls, J. D. Van der (1976): "Beaker Culture in the Lower Rhine Bassin". Glockenbecher Symposion. Oberried 1974. Fibula-Van Dishoeck. Bussum/ Haarlem: 1-80. 
Le Roux, Ch.-T. (1999): L'outillage de pierre polie en metadolerite du type A. Les ateliers de Plusssulien (Côtes-d'Armor). Production et diffusión au Néolithique dans la France de l'ouest et au delà. Travaux du Laboratoire "Anthropologie, Préhistoire et Quaternaire Armoricains". Université de Rennes I.

Luengo, J. M. (1974-1975): "Piezas del Museo HistóricoArqueológico de la La Coruña. Objetos pétreos de la primera Edad de los Metales". Revista del Instituto José Cornide de Estudios Coruñeses, X-XI: 131-142.

MAC WHITE, E. (1951): Estudios sobre las relaciones atlántica de la Península Hispánica en la Edad del Bronce. Publicaciones del Seminario de Historia Primitiva del Hombre. Madrid.

MACIÑEIRA, F. (1947): Bares puerto hispánico de la primitiva navegación occidental. Instituto P. Sarmiento de Estudios Gallegos. Santiago de Compostela.

MARINESCU-Bîlcu (1993): "Les carpates orientales et la Moldavie". Atlas du Néolithique européen. L'Europe orientale. Etudes et Recherches Archéologiques de l'Université de Liége, 45: 191-241.

Martínez Santa-Olalla, J. (1946): Esquema paletnológico de la península hispánica. Publicaciones del Seminario de Historia Primitiva del Hombre. Madrid.

Petrequin, A.M. y Petrequin, P. (1988): Le Neolithique des Lacs. Préhistoire des lacs de Chalain et de Clairvaux (4000-2000 av. J.-C). Ed. Errance. Paris.

Petrequin, P.; Cassen, S.; Croutsch, C. y Weller, O. (1997): "Haches alpines et haches carnacéens dans l'Europe du Ve millénaire". Notae Praehistoriae, 17: $135-150$.

RENFrEw, C. (1978)."Varna and the Social Context of Early Metallurgy". Antiquity, 52: 199-203.

- (1979): Problems in European Prehistory. Edinburgh University Press. Edinburgh.

- (1990): Arqueología y lenguaje. La cuestión de los orígenes indoeuropeos. Ed. Crítica. Barcelona.

Rodríguez Casal, A. (1983): “A mámoa de Monte Campelos e o seu enterramento secundario. Novos datos encol do Megalítico Final gallego". Boletín del Museo Provincial de Lugo, I: 7-17.

- (1990): O megalitismo. A primeira arquitectura monumental de Galicia. Biblioteca de divulgación. Universidade de Santiago de Compostela.

Roussot-LARroque, J. (1976): "Les civilisations néolithiques en Aquitaine”. En J. Guilaine (dir.): La Préhistoire
Française. II. Les civilisations néolithiques et protohistoriques de la France. Ed. CNRS. Paris: 339-350.

Suárez Otero, J. (1997): "Un vaso campaniforme con decoración cordada en Galicia: A Fontenla (Moaña, Pontevedra)". Boletín Auriense, XXV: 9-36.

- (1998): "El puñal de sílex nórdico de Cela: una revisión". Gallaecia, 17: 137-150.

Schultz (1983): The Prehistory of Germanic Europe. New Haven - Yale University Press.

Teodorova, H. (1978): The Eneolithic in Bulgaria in the Fifth Millenium B.C. B.A.R. International Series (Supplementary) 49. Oxford.

Treull, R. (1983): Le Néolithique et le Bronze Ancien egéens. Les problémes stratigraphiques et chronologiques, les techniques, les hommes. École Française d'Athénes. Bocard. Paris.

ThÉvenin, A. (1976): "Les civilisations néolithiques en Alsace et en Lorraine". En J. Guilaine (dir.): La Préhistoire Française. II. Les civilisations néolithiques et protohistoriques de la France. Ed. CNRS. Paris: 422431.

Tilley, C. (1984): "Ideology and power in the midle neolithic of Southern Sweden". En D. Hiller y C. Tilley (eds.): Ideology, Power and Prehistory. Cambridge University Press: 111-146.

TusA, S. (1983): La Sicilia nella preistoria. Sellecio editore. Palermo.

VV.AA. (1989): "L'Anthropologie chalcolithique en Bulgarie". Le premier or de l'Humanité en Bulgarie. 5 e millénaire. Ed. de la Réunion des musées nationaux. Paris: 163-164.

VÁZqueZ VARELA, J.M. (1979): “El horizonte de Rechaba: una nueva fase de la cultura megalítica del noroeste peninsular". Boletin Auriense, IX: 9-26.

WINIGER, J. (1981): "Ein Beitrag zur Geschichte des Beils". Zürcher Seevfersiedlungen Archäeologie in der Schweiz, 12 (45-48): 161-188.

WALls, J. van der (1984): "Bell Beakers in Continental Northwestern Europe (1)”. En J. Guilaine (dir.): L'Age du Cuivre Européen. Civilisations à vases campaniformes. Ed. du CNRS: 3-35.

Whittle, A. (1985): Neolithic Europe: a survey. Cambridge World Archaeology. Cambridge University Press. Cambridge.

ZÁротоскÝ, M. (1992): Streitäxte des mitteleuropäischen Äneolithikums. VCHActa Humaniora. Weinheim.

T. P., 58, n. ${ }^{\circ} 2,2001$ 